\title{
Recycling of Aircraft: State of the Art in 2011
}

\author{
Eylem Asmatulu, Michael Overcash, and Janet Twomey \\ Department of Industrial and Manufacturing Engineering, Wichita State University, 1845 Fairmount, Wichita, KS 67260-0133, USA
}

Correspondence should be addressed to Michael Overcash; mrovercash@earthlink.net

Received 26 September 2012; Revised 28 November 2012; Accepted 2 December 2012

Academic Editor: Alan Chan

Copyright (C) 2013 Eylem Asmatulu et al. This is an open access article distributed under the Creative Commons Attribution License, which permits unrestricted use, distribution, and reproduction in any medium, provided the original work is properly cited.

Recently, the end-of-service life for aging aircraft and related parts has become a key subject in recycling industries worldwide. Over the next 20 years, approximately 12,000 aircraft currently utilized for different purposes will be at the end of service. Thus, reclaiming retired aircraft by environmentally responsible methods while retaining some of the value becomes a significant need. Recycling aircraft components and using these in different applications will reduce the consumption of natural resources as well as landfill allocations. Compared to the production of virgin materials, recycling aircraft will also reduce air, water, and soil contaminations, as well as energy demand. In the present study, we have investigated the environmental benefits of recycling and reusing aircraft components in the same or similar applications as low-energy input materials. During the aircraft recycling, most of the aircraft components can be recycled and reused after reasonable modifications and investments.

\section{Introduction}

"Wastes [end-of-life material] from one industrial process can serve as the raw materials for another, thereby reducing the impact of industry on the environment" (Frosch and Gallopoulos, 1989) [1]. This statement is one of the major motivations for the authors to focus on recycling aircraft and related components. Recycling aircraft is a series of activities: collecting recyclable materials and devices from aircraft that would otherwise be considered waste and sorting and processing those useful materials into raw materials for future aircraft and other industrial applications. Hundreds of recyclable materials are available in aging aircraft, and this number continually increases, based on economic and technological developments in the reuse field. At the end of life (EoL), aircraft are often placed in aircraft graveyards/parking places where these sit and degrade as the result of environmental influences, such as UV light, moisture, and oxygen/ozone. In most cases, the useful materials from aircraft are high tech and should be valued for future production and materials conservation. The following section will focus on aircraft recycling companies, aircraft recycling methodologies, and related references. Environmental benefits associated with aircraft recycling and rising market perception of regained products will be reviewed.
Generally, aircraft are composed of a number of different materials and devices, including long and short carbon and glass fiber composites, wires, aluminum, titanium and steel alloys, foam, textiles and carpet, landing gears, fluids, electronic devices, engines, and other parts. Sometimes the complexity of materials and devices in aircraft (e.g., military, business jet, and civilian) can reduce the recyclability rate; therefore, during the initial design, manufacturers should consider the EoL of aircraft.

\section{Recent Progress in Aircraft Recycling}

Currently a number of aerospace alloys, including aluminum and magnesium-based alloys, as well as nickel, cobalt, and titanium-based alloys, have been produced and used for aircraft manufacturing. Aluminum alloys are mainly copper, zinc, manganese, silicon, and magnesium. The two main classifications of aluminum-based alloys are cast and wrought, both of which are subdivided into heat-treatable and nonheat-treatable categories. Approximately, $80 \%$ of aluminum alloys are produced by the wrought process in the form of sheets and foils that are higher in strength and lower in density, which are desired by the aircraft industry. Among the major aluminum alloys commonly used 
in aircraft and other aerospace applications (helicopters and spacecraft) - 7075, 6061, 6063, 2024, and 5052-the 7075 aluminum alloy is most preferred by the aircraft industry. The composition includes 5.1\%-6.1\% zinc, $2.1 \%-2.9 \%$ magnesium, $1.2 \%-2.0 \%$ copper, and less than $0.5 \%$ of silicon, iron, manganese, titanium, chromium, and other trace metals. These alloys are extensively employed in aircraft fuselages and other engineering structures and compounds in which light weight and corrosion-resistant materials are highly required.

Additionally, specially designed alloys make it possible for the aircraft industry to produce high-strength products for jet engines and airframes where high temperature, pressure, and vibration are included during design and manufacturing. Also, stainless steel, nickel, copper, titanium, and these alloys are the major components of aircraft alloys employed for engine blocks, providing high strength and the ability to perform at particularly high temperatures and pressure [2].

Bombardier became the first original equipment manufacturer to emphasize aircraft dismantling operations and, in turn, obtained a dismantling certification from the Aircraft Fleet Recycling Association (AFRA) in 2010. The company successfully dismantled a CRJ100/200 regional jet, which was recognized by the AFRA as one of the best practices in the field. In August 2010, Bombardier Aircraft Services of Charlotte, North Carolina, disassembled 10 CRJ100/200 regional jets for refurbishing and remarketing useable components for different aircraft companies. They recovered 1,500 reusable parts, including 300 line-replaceable units per jet [3].

Carbon Fiber Remanufacturing (CFR), a company established in 1997 in Whitewater Kansas, specializes in the recycling of carbon fiber of composites. This company generally recycles scrap carbon fibers obtained from the manufacturing process and reuses about 30\% of these in further manufacturing processes to make new composites. CFR utilizes detangling, cutting, and hammer milling processes to remanufacture carbon fiber scraps for different product applications. The recycled carbon fibers are used as secondary raw materials without any mechanical property losses, so the remanufactured carbon fibers are nearly the same as the virgin carbon fibers. These can be cut into specified lengths $(0.6 \mathrm{~cm}-7.5 \mathrm{~cm})$ and integrated into nonwoven rolled cloth products and compounds for preferred specifications. These can be added into fiber-reinforced plastics and polymers to make composites and also blended with glass and Kevlar fibers in order to develop new products. Recycled carbon fibers can be used in structural, insulation (thermal and acoustic), and filtration (air and liquid) applications. CFR provides many recycled materials to local and national aircraft industries, as well as appliances, agriculture, construction, automotive, waste water filtration, trucks, textiles, military equipment, outdoor products, power generation, and sporting goods [4].

Recent studies show that the AFRAs series of best management practice guides have become the industry standard for dismantling and recycling aircraft [5]. Since 2008, 16 companies have been accredited by AFRA worldwide, 10 of which are located in the US and the remaining in Europe [6]. Since these companies were certified by AFRA, they have experience in how to dismantle and disassemble aircraft efficiently. They offer a reliable source of high-quality after market airframe spares to global customers, primarily including avionics, electronics, engines, rotables, landing gear, interior decorations, and other flight control parts [6]. Thus, AFRA is the major accreditation process and provides the aircraft and recycling industries with all necessary procedures and tools in order to maximize environmental efficiency and economic profit during aircraft disassembly. This increases the value of the recyclable aircraft at EoL by developing new technologies and approaches that utilize higher-valued materials and devices from aircraft and other closely related industries.

AFRA and Boeing also intend to reduce the amount of aircraft manufacturing waste transferred to the landfill by $25 \%$ by 2012 . AFRA is the global organization dedicated to environmentally responsible management of airplanes during the EoL service and also to the practice of continual life-cycle improvement. According to the AFRA, the quality of recycled composite materials needs to be improved, and new applications and markets for inside and outside the aviation sector need to be defined. Recycling also makes excellent business sense, because the market desires are satisfied at lower costs [5].

Processing for the advanced management of EoL for aircraft (PAMELA) is a program for aircraft dismantling that is supported by the European Commission's "LIFE" initiative. This dismantling project mainly focuses on subjects, including management, recycling, and reduction of landfills. In this project, the Airbus Company dismantled a 24-year-old airplane (A300B4) into four categories: structure, cockpit/cabin/cargo, systems, and power plant. The main idea behind the project was to increase the amount and quality of materials from retired aircraft. Purity was not the main issue in this project, but the quantity and amount of recovered materials (e.g., mostly nonferrous materials) were considered major advantages. Unlike current processes, dismantling was more efficient and recovered up to $70 \%-80 \%$ of the scrap by weight for reuse. According to Airbus, recovered scrap metals are reasonably pure, so that the recovered aluminium alloys and other parts can be reused directly in the aerospace industry.

In addition to economic returns, recycling has environmental benefits, as well. For example, aluminium manufacturing is an energy-intensive process due to the electrolysis step (or Bayer process). However, when aluminium is directly recovered and reused, it reduces the initial energy by $90 \%$ [7], which in turn also reduces raw material consumption. The dismantling process consists mainly of three steps defined by PAMELA. The first step is decommissioning, which includes cleaning, draining of tanks, and various safety procedures. The second step is disassembling, which consists of equipment and parts removal from the body of the aircraft. The third step is the final draining of the systems, removal of hazardous materials, and deconstruction of the aircraft. According to Airbus, some of the components can be reused if the conditions of the parts are still in good shape, such as engines and engine parts, the auxiliary power unit, landing gear, avionics, system equipment, and movable parts and devices. Many other good-quality materials and 


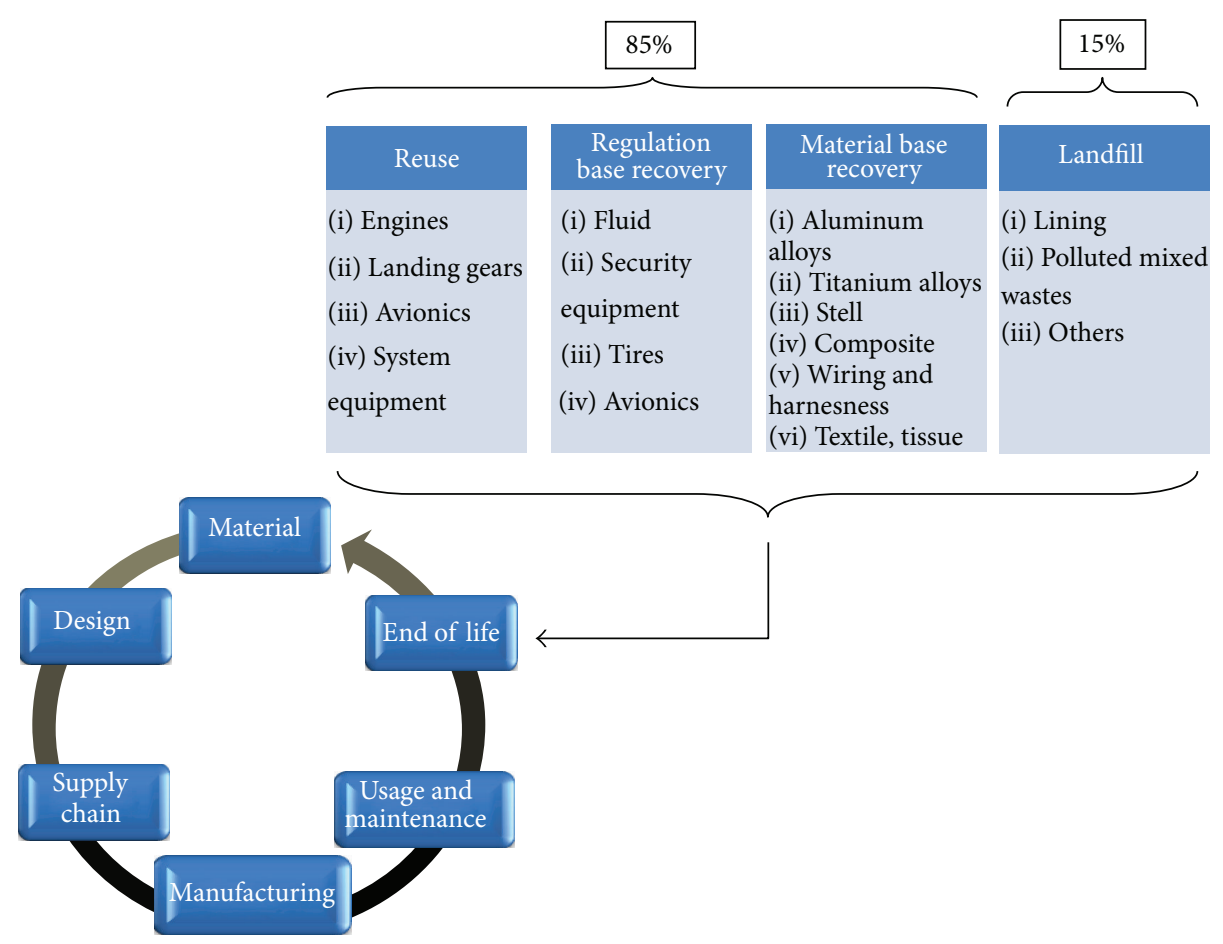

FIGURE 1: Life cycle of aircraft and reverse supply chain for future use as efficient and low-cost materials (adapted from PAMELA-Life Project Led by Airbus) (Airbus France S.A.S., 2008 [7]).

devices can be directly recycled and reused as provided below:

(i) some components, such as fluids (fuel, oil, and hydraulic fluid), security and safety equipment, batteries, avionics, and tires (requiring regulatory recycling);

(ii) aluminum, titanium, and nickel alloys; hot-rolled and corrosion-resistant steel alloys; wiring; harnesses; thermoplastics; foams; textiles; carpeting; papers/tissues with special recycling techniques;

(iii) cabin and cargo lining, wastes, and various other parts that are not recovered and usually go to landfills and aircraft graveyards;

(iv) all composite parts of the aircraft, including the fuselage and interior parts could be potentially utilized in other industries.

(v) the entire aircraft used for demonstrations and exhibitions in shows and museums for raising public attention for aviation.

Figure 1 shows the aircraft life cycle as well as a reverse supply chain of an airplane. It was reported that the initial weight of an average airplane is 106 tons, and, after three steps in the dismantling process, about $85 \%$ of the airplane materials could be recovered and the remaining $15 \%$ put in landfills [7]. The $85 \%$ of the recycled parts are either used, as is, in the same field, or modified for other applications. Further studies are needed for the unrecoverable materials and parts of the aircraft. It was recommended that the remaining $15 \%$ of the components and materials such as interiors could be used in other aircrafts [8-10]. Airbus reported that approximately $€ 250-€ 300$ could be spent per ton of dangerous aircraft parts during storage, such as with asbestos and hexavalent chromium (chromium VI) of the aircraft skin. Lately, Airbus has been persistently working on this subject to further decrease the high costs of the landfill allocations $[8,9]$.

P3 Aviation is the United Kingdom-based supplier of rotating components (e.g., engines, actuators, turbines, generators, and alternators), aiming to take advantage of the growing market for dismantling and recycling aircraft. This company supervises the removal process from aircraft during the deregistering, dismantling, and selling of parts at the highest values. The company has already dismantled seven aircraft in 2010 and successfully turned aircraft scraps and cabin parts into cash. According to the company, the interior part of the aircraft generally goes to the landfill, but they have sold entire interiors of Boeing 737-400 airplanes. The company also sells diverse aircraft parts for use as office furniture and for decoration purposes. The fuselage has been utilized for desk partitions, flaps and stabilizers for boardroom tables, and engine inlet cowls as reception desks in bars and restaurants [10].

With the aim of recycling plastics and composite materials from aircraft, Allred and Salas (2005) investigated a lowtemperature catalytic tertiary recycling process. They claim that the catalytic conversion process could transform all types of plastics (e.g., rubber, thermosets, and thermoplastics) into valuable hydrocarbon products and fuels. Catalytic conversion, a closed-loop process without access to the 
environment, is nonpolluting because of the rapid conversion times. Other experiments on the utilization of used plastic blast media, hazardous waste streams, and composite scraps and parts involve a low-temperature catalytic conversion process. It was stated that using this conversion process for recycled plastics and other hydrocarbon-associated materials could reduce hazardous substances by a factor of five. Inorganic parts, such as heavy metals and other oxides, could be remelted to eliminate toxicity and used in aircraft. Imide, polyester, epoxy, and other engineered thermoplastics and composite matrices could be converted into low-molecularweight hydrocarbons to produce valuable fibers for reuse in the fabrication of additional composite materials for aircraft and other industries. Economic analysis illustrates that a recycling plant based on this method will have a return on investment of one to two years. An interrelated technology illustrated a significant amount (100 ton/day) of recycled tires used, confirming that there is a high possibility of implementation with a large-scale tertiary recycling of plastics and composites [11].

It is reported that the recycling of cured composite materials used for aircraft manufacturing is a difficult process because of the complexity of the composite structures [12]. These materials are produced using thermosetting epoxy matrices that form an intimate connection with the surfaces of fibers, metals, and coatings. Recent techniques developed to recycle thermoset composites were recently reviewed [12]. Because of the structural concerns of these recycled fibers, the materials may not regain the original values of reinforcing fibers in order to be directly used in the fuselage structures of aircraft.

The Boeing and Alenia Aeronautica companies founded Italy's first aircraft composite recycling facility of materials for future manufacturing. This facility processes an average of 1,102 tons of composite scrap yearly and creates roughly 75 jobs in the regional economy. Boeing also cooperated with Milled Carbon Limited to establish a pilot industrial plant for processing cured and uncured composite parts on a continuous basis in order to extract high-quality carbon fibers. The recycled material is likely to be utilized for noncritical structures of aircraft, such as galleys, interior linings, seat parts, and tools that produce stronger and lighter-weight materials in the same industry [13].

Most of the wires used in aircraft are conductive metals (e.g., copper, silver, and aluminum) of various sizes and shapes, covered by plastic insulators. Recently, fiber optic cables have been used in aircraft manufacturing, as well. Among the wires and cables, copper is the most commonly used for electrical wiring in aircraft. It was reported that the Boeing Dream Liner 787 has about 60 miles of cables, while Boeing 777 has about 100 miles of cables (Boeing, 2008 [13]). Once the metal wires are properly removed from aircraft, recycling is easier. Larger-scale wires are shredded and then granulated into smaller particles, so that separators (e.g., gravity, electrical, and optical) can remove the metals from the plastic parts. For instance, an eddy-current separator is one of the frequently utilized electrical separators in which granulated copper wires are fed into the separator to remove copper particles from the plastic particles. Both of these materials can be used in aircraft after the melting and reprocessing steps. For very thin copper wires, the recycling process becomes quite complex. In this case, burning the plastic part of the wires can be the main option for metal recovery, and the heat produced during the burning process can be used in the same industry as an energy source. Depending on the size and complexity of the wires and recycling methods, the recovery rate of wires and cables can vary from $50 \%$ to $90 \%$, or even more [14].

Yi et al. (2008) offered an algorithm on the disassembly strategy of mechanical parts in aircraft that relies on the disassembly wave concept [14]. This method is relatively simple and also efficient to search and develop. Furthermore, the method offers an optimal and selectable disassembly sequence of mechanical components with lower numbers of computing and processing steps. This is considered to be a very significant process for maintaining, recycling, and discarding aircraft parts. The authors conducted a study of wave propagation for the selectable disassembly analysis. They claimed that the wave propagation method provides an optimal sequence to disassemble the selected components with the wave that propagates from the selected component to a set of boundary components. The authors also discussed geometric algorithms for both single-dependent and multiple-dependent components. The major drawback of the study was the identification of an optimal sequence used for the selected items with the minimal component removals and examining a division of components from the assembly [15].

\section{Marketability of Recycled Aircraft Materials}

The major components that can be recycled from aircraft include wires, electronics, aluminum and other alloys, stainless steel, other organic and inorganic compounds, and carbon and glass fibers [16]. Recycling offers economic and environmental benefits because of less energy consumption, labor, and emissions (solid, liquid, and air). Figure 2 shows aluminum sheets that were recycled from aircraft and used for aluminum tile products. The energy consumption of the recycling process is $5 \%$ of that required for first-generation aluminum production. Service scrap and manufacturing scrap can be recycled and reused to reduce the consumption of natural resources and mining operations worldwide [17]. Another direct application (described in an unreviewed blog) of the recycled product is in iPad cases, which are made of a solid block of recycled aircraft aluminum [18].

Carbon fibers recycled from a military aircraft (F18) were aligned and integrated into a compression molding unit to make new composites. Materials Innovation Technologies (MIT), located in Fletcher, North Carolina, fabricated automotive parts from recycled fibers using chopping, mixing, and molding processes. Chopped composite parts from the F18 were delivered to both Milled Carbon and Adherent Companies. These fine composites were successfully injection molded to produce different components for testing and evaluation. Test results confirmed that the mechanical strength of the injection molded parts closely matched the shelf virgin carbon fiber-filled compounds. Figure 3 shows a 


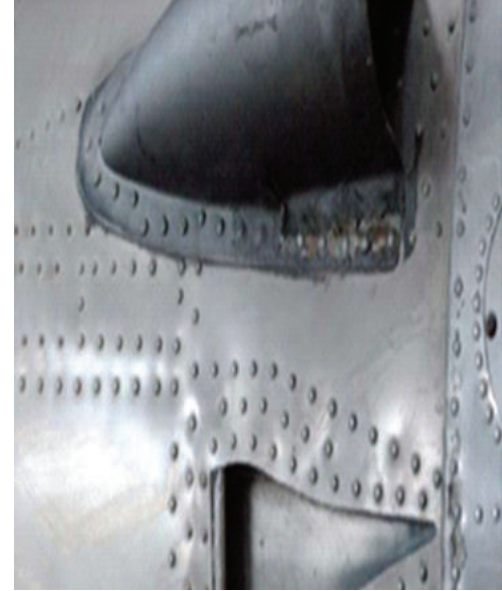

(a)

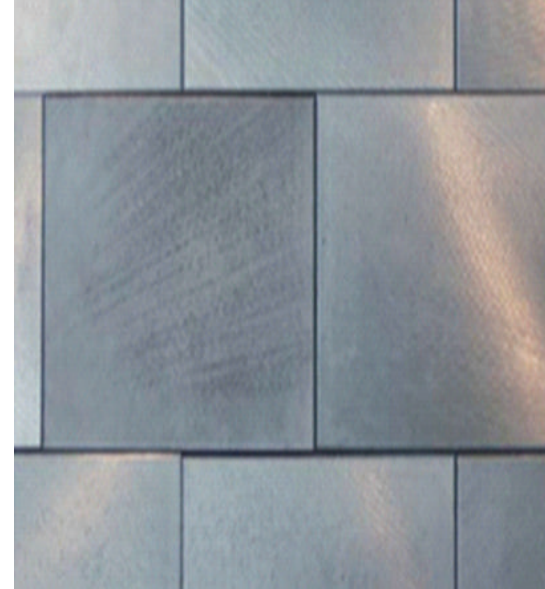

(b)

FIGURE 2: Photographs showing aluminum sheets recycled from an aircraft (a) and reused as tiles (b) (source: http://www.coveringsetc.com/).

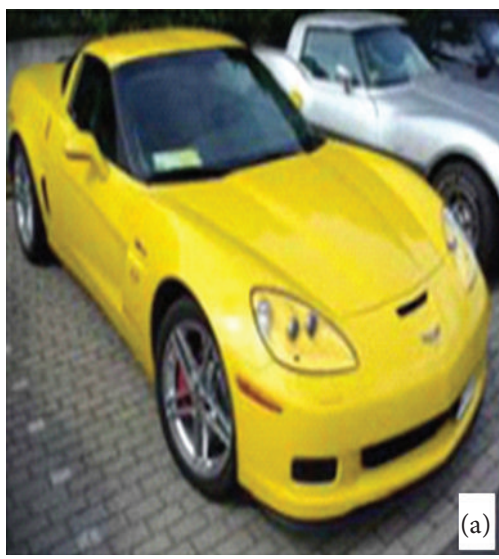

(a)

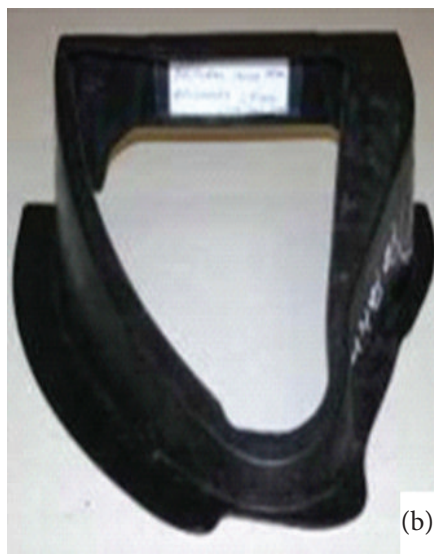

(b)

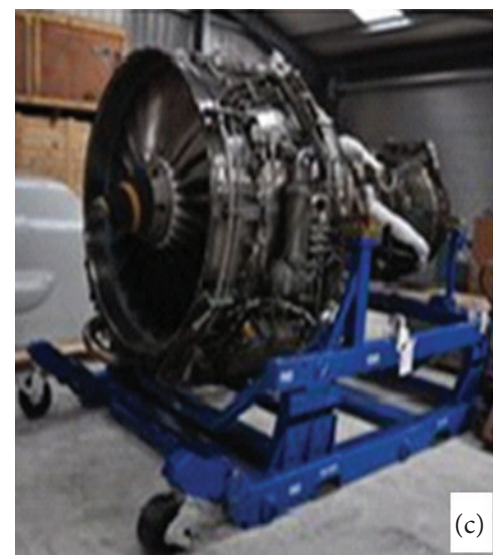

(c)

Figure 3: Corvette C6 fender well component (a) molded from recycled F18 carbon fiber (b); removed aircraft engine (c) at recycling facility (source: George and Carberry, 2007 [19]).

Corvette C6 fender well component molded from recycled F18 carbon fiber, as a demonstration project. As can be seen, the Corvette component (Figure 3(a)), produced from recycled carbon fiber (Figure 3(b)), is about 20\% lighter than the fiberglass components, even without any engineering processes. The stiffness of the new composites was also significantly enhanced by adding the recycled fibers [19]. The recycled and remolded products are currently being utilized in the car.

Lastly, an aircraft engine can comprise up to $80 \%$ of the total value of the aircraft, depending on the applications for which it will be used. According to Mark Gregory of Air Salvage International (ASI), the remaining part of the plane can be sold as spares for approximately $\$ 350,000$ [20]. Engines (Figure 3(c)) are the first items to be taken out of an aircraft at the recycling facility. These are first checked and then investigated for further use in another airplane. Most of these high-tech materials (e.g., nickel, cobalt, and chromium alloys) with very high mechanical strength and high temperature and corrosion resistance are placed in aircraft engines, so the recycling value of these materials is considerably higher than other aircraft parts [20].

\section{Environmental Impacts of Aircraft Recycling}

By reducing the amount of energy used by the aircraft industry, recycling reduces greenhouse gas (GHG) emissions and minimizes global climate change. Additional benefits of recycling would be a reduction in emissions from incinerators, and lesser materials to fill the landfills. Table 1 shows the energy savings of different recycled aircraft materials in the US. For example, copper and aluminum recycling from scrap has $85 \%$ and $95 \%$ less energy requirement, respectively [21]. Utilizing secondary raw materials reduces the use of natural resources. The third column of Table 1 shows the energy savings of recycling metals and related materials. Compared to the concentrating that occurs in mineral processing facilities and the smelting that goes on 
TABLE 1: Energy savings of recycled materials in comparison to virgin production and percentage of new metals produced by using recovered metals (source: Lund, 2000 [21], and BMRA, 2011 [22]).

\begin{tabular}{|c|c|c|c|}
\hline $\begin{array}{l}\text { Recycled } \\
\text { materials }\end{array}$ & $\begin{array}{l}\text { Separation } \\
\text { techniques }\end{array}$ & $\begin{array}{l}\text { Energy } \\
\text { savings } \\
(\%)\end{array}$ & $\begin{array}{c}\text { New metals produced by } \\
\text { using recovered metals } \\
(\%)\end{array}$ \\
\hline Steel & $\begin{array}{l}\text { Hand sorting, } \\
\text { magnetic }\end{array}$ & $62-74$ & 42 \\
\hline Aluminum & $\begin{array}{l}\text { Electrostatic, } \\
\text { Hand sorting, } \\
\text { Eddy current }\end{array}$ & 95 & 39 \\
\hline Copper & $\begin{array}{l}\text { Electrostatic, } \\
\text { Eddy current, } \\
\text { hand sorting }\end{array}$ & 85 & 32 \\
\hline Lead & $\begin{array}{c}\text { Gravity, } \\
\text { hand sorting }\end{array}$ & $60-65$ & 74 \\
\hline Zinc & $\begin{array}{l}\text { Gravity, } \\
\text { hand sorting, } \\
\text { flotation }\end{array}$ & 60 & 20 \\
\hline Paper & $\begin{array}{l}\text { Flotation, } \\
\text { hand sorting }\end{array}$ & 64 & $\mathrm{~N} / \mathrm{A}$ \\
\hline Plastics & $\begin{array}{l}\text { Electrostatic, } \\
\text { Eddy current, } \\
\text { hand sorting }\end{array}$ & 80 & N/A \\
\hline
\end{tabular}

in metallurgical plants, recycling needs only about $10 \%$ of the total investment, increases employment, facilitates the sustainment of a practical manufacturing base, and eradicates landfill waste $[22,23]$.

Damgaard et al. (2009) assessed greenhouse gas emissions associated with the recycling of metals from after consumer waste in the frame of waste management. A material recovery facility (MRF) was used for the sorting of the recovered metal. According to the authors, GHG emissions are derived from three sources: indirect upstream emissions, direct activities at the MRF, and indirect downstream processes needed in reprocessing the metal scrap. Energy savings result from the avoided production of virgin metal. The global warming factor (GWF) of the upstream activities and the $\mathrm{MRF}$ as GHG emissions were $12.8-52.6 \mathrm{~kg} \mathrm{CO} /$ ton recovered aluminum and $400-1020 \mathrm{~kg} \mathrm{CO} /$ ton recovered steel. Reprocessing is associated with a large saving as the result of avoided virgin production of aluminum and steel. The authors defined a net downstream savings of 5,040-19,340 kg $\mathrm{CO}_{2} /$ ton of the treated aluminum and $560-2360 \mathrm{~kg} \mathrm{CO}_{2} /$ ton of the treated steel. The authors concluded that recovery of the scrap metal mainly relies on the technology and method chosen during the recycling processes, which make the comparison a little more difficult. Energy usage during the recovery and the avoidance of energy used in primary production are also important issues [24].

Other studies have confirmed that regained fibers from recycling serve as feasible replacements for new fibers within many high-end industrial manufacturing processes and also offer a noteworthy savings of money and carbon dioxide emissions. Recycled carbon fiber can be made at about $70 \%$ of the cost with $98 \%$ less energy than manufacturing virgin chopped fiber. It is estimated that commercial jet
TABLE 2: Evaluation of virgin and recycled carbon fiber (source: Carberry, 2011 [19]).

\begin{tabular}{lcc}
\hline & \multicolumn{2}{c}{ Cost to manufacture } \\
& $\begin{array}{l}\text { Materials } \\
\text { (US } \$ / \mathrm{lb})\end{array}$ & $\begin{array}{c}\text { Energy } \\
(\mathrm{kWH} / \mathrm{lb})\end{array}$ \\
\hline Virgin carbon fiber & $15-30$ & $25-75$ \\
Recycled carbon fiber & $8-12$ & $1.3-4.5$ \\
\hline
\end{tabular}

TABLE 3: Environmental impact associated with production of one kg of carbon fiber (source: Åström, 2005 [26]).

\begin{tabular}{lccccc}
\hline $\begin{array}{l}\text { Energy } \\
\text { source }\end{array}$ & $\mathrm{MJ} / \mathrm{kg}$ & $\begin{array}{c}\mathrm{CO}_{2} \\
(\mathrm{~kg})\end{array}$ & $\begin{array}{c}\mathrm{NO}_{X} \\
(\mathrm{~kg})\end{array}$ & $\begin{array}{c}\mathrm{SO}_{X} \\
(\mathrm{~kg})\end{array}$ & $\begin{array}{c}\text { Environmental impact } \\
(\mathrm{ELU})\end{array}$ \\
\hline Electricity & 200 & 26.8 & 0.06 & 0.1398 & 7.8 \\
Oil & 200 & 39.8 & 0.0363 & 0.0302 & 12 \\
\hline Total & 400 & 66.6 & 0.0936 & 0.17 & 19.8 \\
\hline
\end{tabular}

manufacturing will create up to two million pounds of carbon fiber scrap in 2014. Recycling and substituting carbon fiber for virgin fiber in manufacturing and applications would save enough electricity to power 175,000 typical homes in a year $[16,17]$.

According to Jim Stike, CEO of the recycling firm Materials Innovation Technologies, using recycled carbon fiber not only avoids the waste of virgin carbon fiber being sent to landfills after the first use but also produces new parts because carbon can maintain a significant portion of the virgin properties even after a second reclamation. As well, the recycling process for the fibers reduces energy costs. Based on Boeing's estimates, carbon fiber can be recycled at approximately 70 percent of the cost to produce virgin fiber (Table 2) (\$8/lb-\$12/lb versus $\$ 15 / \mathrm{lb}-\$ 30 / \mathrm{lb})$, using about 5 percent of the electricity required $(1.3-4.5 \mathrm{kWH} / \mathrm{lb}$ versus $25-75 \mathrm{kWH} / \mathrm{lb})$. In addition, MIT is willing to capitalize on the potential high quality of the recycled chopped carbon fiber to efficiently create intermediate-modulus materials that can be used instead of virgin aerospace and industrialgrade products [25]. Table 3 shows the environmental impact (environmental load unit, ELU) of virgin carbon fibers on energy consumption during the manufacturing process [26]. In order to produce $1 \mathrm{~kg}$ of virgin carbon fiber, $400 \mathrm{MJ}$ of total electrical energy (equivalent to oil) is required. Avoiding higher energy in the conventional virgin processes will reduce gas emissions because the energy is mainly from fossil fuels, so recycling makes a substantial improvement on the environment [26].

Aircraft recycling activities in the world promote development of communities and social interactions between communities. Other social impacts consist mainly of an increased lifespan made possible through a cleaner environment, safer working conditions for employees and employers; increased citizen interest in seeking employment or volunteer work in recycling, and improved scientific, cultural, and other activities nationally and internationally. Recently, social as well as educational impacts of recycling have been gaining much attention globally. 


\section{Limitation and Future Research}

Recycling provides a number of different benefits to the environment and economy. For use as interior materials of aircraft, recycling competes with the option of disposal [5]. Although the AFRA emphasizes this issue, several companies are already reusing aircraft interior parts for furniture, decoration, and art components. One of the dismantling programs is based on the A300-B4 airplane, which contains $4 \%$ composites, $4 \%$ titanium, $12 \%$ steel, $77 \%$ aluminum, and $3 \%$ other materials, so this specific model contains a high ratio of aluminum (77\%), while later models contain a high ratio of composites. Thus, a better composite recycling process for higher composite-containing airplanes should be investigated for each airplane. The most efficient recycling methods need to be defined for composite materials of various sizes and shapes and marketability should be sought in detail [27].

For more than four decades, thousands of obsolete aircraft have been sitting in the Southwest desert; however, the demand for recycled aluminum is still increasing. The abandoned aircraft have great potential as a source of valuable metals and fibers for several industrial applications. Nevertheless, cost-effective recycling of aircraft alloys is difficult due to the fact that these characteristically have quite high levels of alloying elements, such as zinc (7xxx series) and copper (2xxx series), and low levels of minor elements, in order to optimize fracture toughness and other mechanical and corrosion properties. Changing the structure and types of aircraft materials makes the recycling process more complex and challenging [28].

According to Das (2009) feasible aluminum recovery is $90 \%$ or greater for the older aircraft. Aluminum alloys contain high amounts of zinc and copper, which makes the recycling process more complicated than the lesser-alloyed aluminum and other alloys used in other applications. Specific recycling trials are needed to make aircraft recycling more economic and efficient [29]. From a market point of view, the recycling of glass fiber is not practical because of its low cost $(<\$ 1 / \mathrm{lb})$ and a sufficient supply of virgin glass fiber available to the market. However, recycled carbon fibers have a higher demand in the market because of the lower cost and similar physical properties compared to the virgin fibers, so it is economically more feasible for many companies [30]. Lastly, the design stage is very important due to the cost of raw materials and recyclability of products. Designing a product in a reliable and recyclable way should be investigated in detail for each aircraft produced.

\section{Conclusion}

Recycling aircraft parts offers numerous environmental benefits, including reduction of water, soil, and air pollution, as well as landfills. Some of the materials (composites and alloys) in aircraft are costly to produce, so regaining these kinds of materials at a reasonable price is an environmentally responsible approach is of great interest to recycling and aircraft industries. Aluminum is a high-demand material for most industries, so recovering this material with less effort has gained the considerable interest of many industries. Recycling of a material requires less energy than that of producing virgin material and also reduces gas emissions (e.g., $\mathrm{CO}_{2}, \mathrm{CO}, \mathrm{NO}_{X}$, and $\mathrm{SO}_{2}$ ) and other emissions. A direct recycling (or as is recycling) methodology can be used for some aircraft components, such as engines and electronics. Also, using aircraft components for furniture and decoration requires less energy because it necessitates only some basic processes such as cutting, reshaping, sanding, and painting, in order for these to be turned into sophisticated furniture for many consumers.

\section{Abbreviations}

AFRA: Aircraft Fleet Recycling Association

ASI: Air Salvage International

CFR: Carbon Fiber Remanufacturing

EoL: $\quad$ End of life

GHG: Greenhouse gas

GWF: Global warming factor

MIT: Materials Innovation Technologies

MRF: Material Recovery Facility.

\section{References}

[1] R. A. Frosch and N. E. Gallopoulos, "Strategies for Manufacturing," Scientific American, 1989, http://www.umich.edu/ nppcpub/resources/compendia/IEORpdfs/IEOR_Reading.pdf.

[2] J. R. Davis, Aluminum and Aluminum Alloys-ASM Specialty Handbook, ASM International, 1993.

[3] Bombardier. Recyclability "End-of-Life Challenges,“, 2011, http://csr.bombardier.com/en/products/aerospace-products/ recyclability.

[4] Carbon Fiber Remanufacturing (CFR), "Guide to Reclaimed Carbon Fiber Market Applications," 2011, http://www .carbonfiberremanufacturing.com/.

[5] Aerospace Manufacturing and Design (AMD), "AFRA Targets 90\% Recyclability of Global Fleet by 2016," 2011, http://www.onlineamd.com/aerospace-manufacturing-designAFRA-recyclability-amd-070210.aspx.

[6] Aircraft Fleet Recycling Association (AFRA), "AFRA Accredited Companies," 2012, http://www.afraassociation.org.

[7] Airbus, France S.A.S. "PAMELA-Life Main Project Result" 2008, http://www.pamelalife.com/english/results/PAMELALife-project_results-Nov08.pdf.

[8] M. Kingsley-Jones, "Airbus's Recycling Master Plan-Pamela," Flight International, 2008, http://www.flightglobal.com/ articles/2008/05/26/224015/airbuss-recycling-master-planpamela.html.

[9] Tarmac Aerosave, "First Industrial Company for Aircraft Storage and Dismantling," 2011, http://www.tarmacaerosave .aero/TARMAC_Aerosave_en.pdf.

[10] K. Reals, "Dismantling Company Finds Innovative Ways of Reusing Scrapped Aircraft Materials," 2011, http://www.flightglobal.com/articles/2011/01/10/351596/dismantling-company-finds-innovative-ways-of-reusing-scrapped-aircraft.html.

[11] R. E. Allred and R. M. Salas, "Recycling Process for Aircraft Plastics and Composites," 2011, http://www.dtic.mil/cgibin/ GetTRDoc?AD=ADA305806\&Location $=$ U2\&doc $=$ GetTRDoc .pdf. 
[12] E. Asmatulu, J. Twomey, and M. Overcash, "Recycling of fiber reinforced composites and reusing in different fields as low cost products," Journal of Composite Materials. In press.

[13] Boeing, "Boeing and Alenia to Support Italy's First Composite Industrial Recycling Plant," 2008, http://www.boeing.com/ news/releases/2008/q3/080715e_nr.html.

[14] J. Yi, B. Yu, L. Du, C. Li, and D. Hu, "Research on the selectable disassembly strategy of mechanical parts based on the generalized CAD model," International Journal of Advanced Manufacturing Technology, vol. 37, pp. 599-604, 2008.

[15] Anonymous 1, "Electric Wire Recycling," 2011, http://www .profitablerecycling.com/ElectricWireRecycling.htm.

[16] W. Carberry, "Airplane Recycling Efforts Benefit Boeing Operators," 2011, http://www.boeing.com/commercial/aeromagazine/articles/qtr_4_08/pdfs/AERO_Q408_article02.pdf.

[17] Coveringsetc, "Recycled Airplane Parts Transformed into Bio-Luminum," 2011, http://www.coveringsetc.com/BioLuminumHome.aspx?CategoryID=22.

[18] Anonymous 2, "DrawCase for iPad," 2011, http://www.topblogposts.com/2010/06/showcase-of-beautiful-apple-ipadcases/.

[19] P. E. George and W. L. Carberry, "Recycled carbon fiber performance in epoxy and polycarbonate matrices," in Proceedings of the Composites Innovation Conference, Barcelona, Spain, October 2007.

[20] M. Cacciottolo, "How do you recycle jumbo jet," $B B C$ News, 2011, http://news.bbc.co.uk/2/hi/uk_news/magazine/ 8542482.stm.

[21] H. Lund, Recycling Handbook, McGraw-Hill Professional, 2nd Edition edition, 2000.

[22] British Metals Recycling Association (BMRA), "About Metal Recycling," 2011, http://www.recyclemetals.org/about_ metal_recycling.

[23] S. K. Das, J. A. S. Green, and J. G. Kaufman, "Aluminum Recycling: Economic and Environmental Benefits," 2011, http://www.phinix.net/services/Recycling/Aluminum_Recycling_Economic.pdf.

[24] A. Damgaard, A. W. Larsen, and T. H. Christensen, "Recycling of metals: accounting of greenhouse gases and global warming contributions," Waste Management and Research, vol. 27, no. 8, pp. 773-780, 2009.

[25] K. Wood, "Carbon Fiber Reclamation: Going Commercial," High-Performance Composites, 2011, http://www.compositesworld.com/articles/carbon-fiber-reclamation-going-commercial.

[26] A. H. Åström, Model for end of life treatment of polymer composite materials [Doctoral Thesis], Department of Machine Design, Royal Institute of Technology, Stockholm, Sweden, 2005, kth.diva-portal.org/smash/get/diva2:12611/FULLTEXT01.

[27] P. B. Hayes, "Europe Pioneers Aircraft Recycling Initiatives," Industry Beat, pp. 4, 2006, http://www.aiaa.org/ aerospace/images/articleimages/pdf/AA_Aug06_IB.pdf.

[28] S. K. Das, J. A. S. Green, J. G. Kaufman, D. Emadi, and M. Mahfoud, "Aluminum recycling-an integrated, industry wide approach," The Minerals, Metals \& Materials Society (TMS), vol. 62, no. 2, 2007.

[29] S. K. Das, "Aluminum recycling: an integrated industry-wide approach," in AIME Conference, pp. 22-24, Lausanne, Switzerland, July 2009.

[30] V. Patel, "Composites Recycling: Market Opportunity Analysis," 2011, http://www.frptoday.in/APRIL\%202010.pdf. 

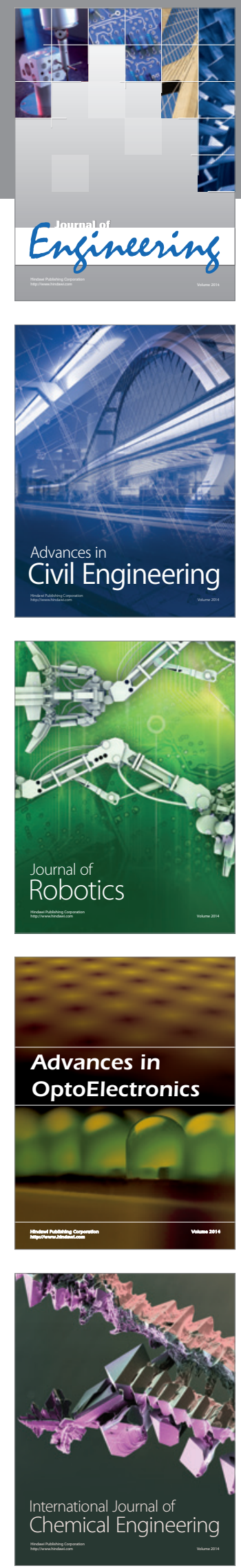

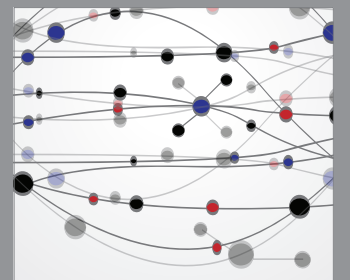

The Scientific World Journal
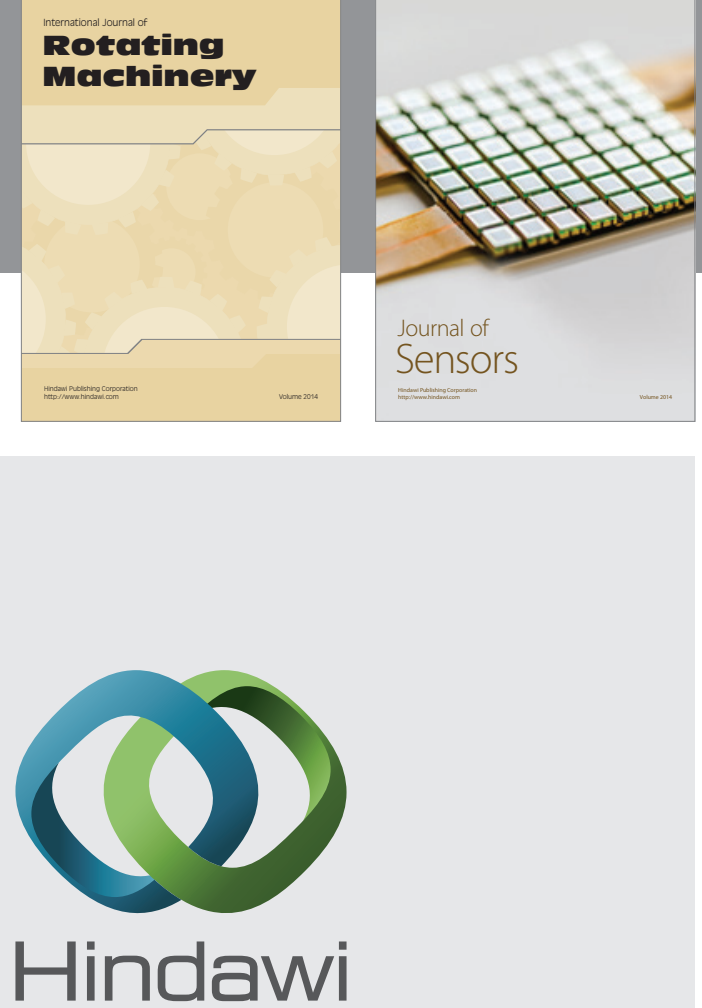

Submit your manuscripts at http://www.hindawi.com
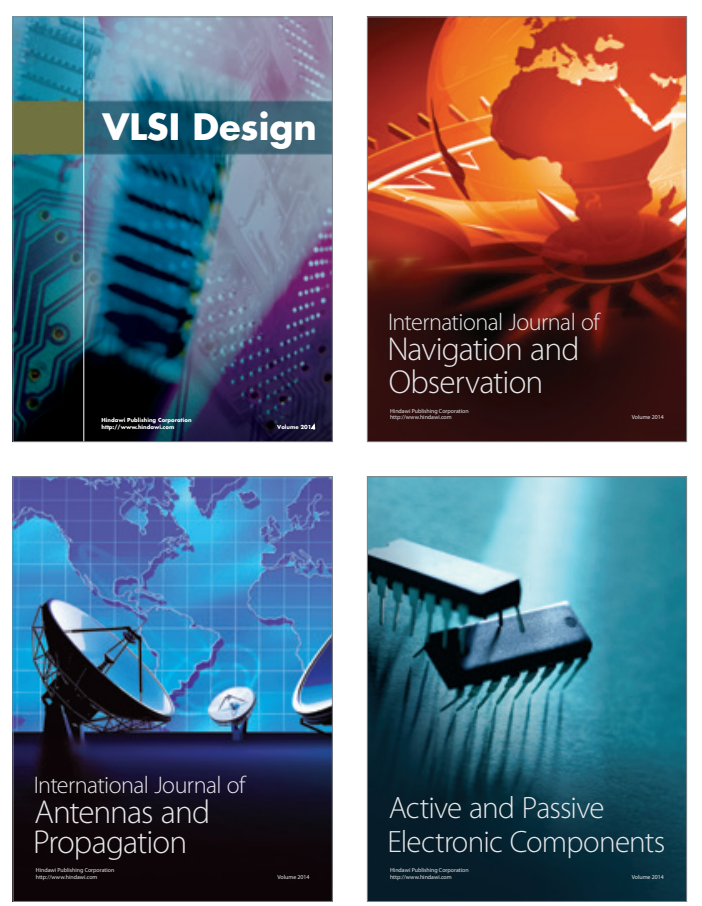
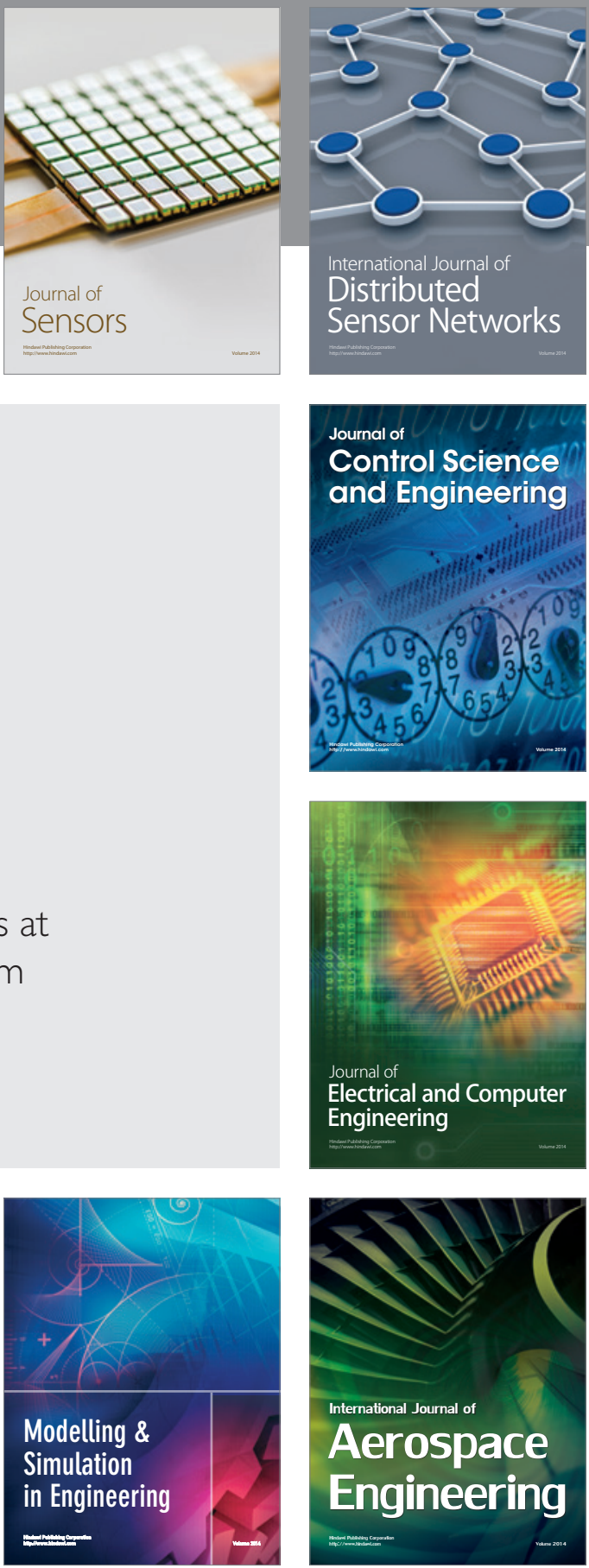

Journal of

Control Science

and Engineering
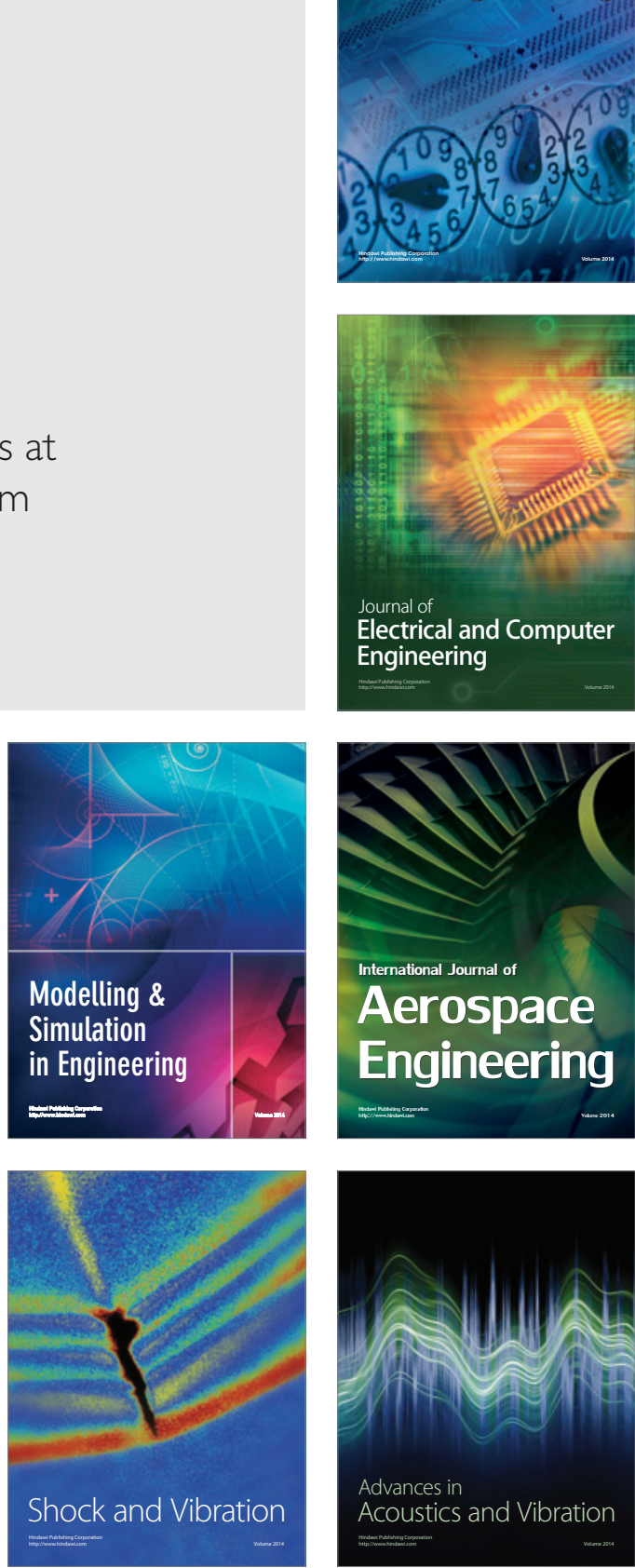